\title{
Outcomes Following Exploratory Burr Holes for Traumatic Brain Injury in a Resource Poor Setting \\ Jessica Eaton ${ }^{1}$, Asma Bilal Hanif ${ }^{2}$, Gift Mulima ${ }^{2}$, Chifundo Kajombo ${ }^{2}$, Anthony Charles $^{1-3}$
}

BACKGROUND: Traumatic brain injury (TBI) is a leading cause of death and disability worldwide. The incidence of TBI in low- and middle-income countries (LMICs) is disproportionately high, with an associated increased risk of mortality from $\mathrm{TBI}$ relative to high-income countries. Although computed tomography is the diagnostic method of choice, this is often unavailable in LMICs. Exploratory burr holes may provide a suitable choice for diagnosis and treatment of TBI.

METHODS: We performed a retrospective review of prospectively collected data at $\mathrm{KCH}$, a tertiary care center in Lilongwe, Malawi. All trauma patients presenting between June 2012 and July 2015 with a deteriorating level of consciousness and localizing signs and who underwent exploratory burr holes were included. Additionally, we included all patients admitted with $\mathrm{TBI}$, requiring higherlevel care during 2011. No patients underwent exploratory burr hole during this time. We performed logistic regression to identify predictors of mortality in the total population of TBI patients.

RESULTS: Among the 241 patients who presented to KCH with $\mathrm{TBI}$ requiring higher-level care, the total mortality was $16.4 \%$. More than half $(163$, or $68 \%)$ underwent exploratory burr hole with a mortality of $6.8 \%$. Mortality in patients who did not undergo exploratory burr hole was 43.9\%. Upon adjusted logistic regression, not undergoing exploratory burr hole significantly increased the odds of

\footnotetext{
Key words

- Global neurosurgery

- Low- and middle-income countries

- sub-Saharan Africa

- Trauma

- Traumatic brain injury
}

\author{
Abbreviations and Acronyms \\ Cl: Confidence interval \\ CT: Computed tomography \\ GCS: Glasgow Coma Scale \\ HDU: High-dependency unit \\ ICP: Intracranial pressure \\ ICU: Intensive care unit \\ KCH: Kamuzu Central Hospital \\ LMICs: Low- and middle-income countries
}

mortality (odds ratio $=12.0, P=0.000,95 \%$ confidence interval $=4.48-31.9$ ).

CONCLUSION: Exploratory burr holes remain an important diagnostic and therapeutic procedure for TBI in LMICs. Exploratory burr hole technique should be integrated into general surgery education to attenuate TBI-related mortality.

\section{INTRODUCTION}

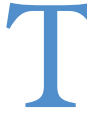
rauma is a leading cause of death and disability worldwide, accounting for 4.7 million deaths annually, ${ }^{\mathrm{I}}$ and is projected to become $\mathrm{I}$ of the top 20 causes of death by 2030. ${ }^{2}$ An estimated $90 \%$ of these deaths occur in low- and middle-income countries (LMICs). ${ }^{3}$ The most common cause of death due to trauma is injury to the central nervous system, ${ }^{4}$ most often in the form of traumatic brain injury (TBI).

The fundamental principles of TBI management are early detection and prevention of secondary brain injury. ${ }^{5}$ Early computed tomography (CT) of moderate to severe TBI patients, defined as a Glasgow Coma Scale (GCS) score of $9^{-1}$ i and $\leq 8$, respectively, is generally recommended. ${ }^{6}$ Patients found to have extra-axial hematomas with midline shift of $>5 \mathrm{~mm}$ require operative intervention. It is well established that early decompression of such lesions improves mortality and functional outcomes. ${ }^{7,8}$ However, in the absence of a CT scanner, clinical signs can still be reliably used to determine the need for emergent

OR: Odds ratio

TBI: Traumatic brain injury

From the ${ }^{\mathbf{1}}$ UNC-Project Malawi, Lilongwe; and ${ }^{\mathbf{2}}$ Department of Surgery, Kamuzu Central Hospitals, Lilongwe, Malawi; and ${ }^{3}$ Department of Surgery, University of North Carolina, Chapel Hill, North Carolina, USA

To whom correspondence should be addressed: Anthony Charles, M.D.

[E-mail: anthchar@med.unc.edu]

Citation: World Neurosurg. (2017) 105:257-264

http://dx.doi.org/10.1016/j.wneu.2017.05.153

Journal homepage: www.WORLDNEUROSURGERY.org 
operative intervention. Patients with deteriorating mental status, a unilateral fixed and dilated pupil, and contralateral hemiparesis warrant immediate intracranial decompression and evacuation of a likely hematoma. ${ }^{9}$

There is a dearth of CT scanners in many resource-poor settings due to cost. There is only I CT scanner per 3.5 million people in LMICs versus I per 64,900 people in high-income countries, ${ }^{\text {IO }}$ and even when available, access is often limited due to infrastructural issues such as lack of consistent electricity and shortage of properly trained technicians. The utility of exploratory burr holes has been established by neurosurgeons in a resource-poor setting with an absence of diagnostic adjuncts, ${ }^{\text {II }}$ in settings where scanners are transiently unavailable, ${ }^{\mathrm{I} 2}$ and by general surgeons in remote locations, particularly in patients deemed too unstable for transport to a neurosurgical center. ${ }^{\mathrm{I} 3}$ Although many head-injured patients in Africa may benefit from exploratory burr holes, the only data available from an African center comes from a retrospective report of 23 procedures performed at a referral hospital in Northern Benin with a mortality of $39.1 \%$. ${ }^{\text {I4 }}$ Given the paucity of data on TBI outcomes in sub-Saharan Africa, we sought to characterize clinical and functional outcomes following exploratory burr holes for TBI at our sub-Saharan African tertiary care center.

\section{METHODS}

This is a retrospective review of prospectively collected data. All trauma patients who underwent an exploratory burr hole procedure between July 2012 and June 2015 at Kamuzu Central Hospital $(\mathrm{KCH})$ were included in the primary study population. Additionally, data on all head-injury patients requiring higher-level care in either the high-dependency or intensive care unit during $201 \mathrm{I}$ were gathered from our trauma surveillance database, a registry of all injured patients presenting to $\mathrm{KCH} .{ }^{\mathrm{I}}{ }^{5}$ The trauma database captures the anatomic location of up to 3 injuries for each patient, with Injury I being the patient's most severe. All patients whose most severe injury was affecting the head, face, or skull and who had an associated altered level of consciousness were included in this population.

This population was selected for comparison because of the absence of a neurosurgeon in 20II, and hence exploratory burr holes were not performed. By selecting only patients who required higher-level care, we captured a population that would have likely been appropriate to consider for exploratory burr holes, had a neurosurgeon been available.

For exploratory burr hole patients, age, gender, and mechanism of injury were recorded. GCS was noted, and localizing signs and symptoms prompting the procedure were captured. Perioperative findings, as well as pertinent findings on postoperative CT scan, were recorded. At discharge the patient's Glasgow Outcome Score $^{\mathrm{I} 6}$ was assessed and recorded by the attending neurosurgeon. For the cohort of patients admitted in 20II, age, gender, mechanism of injury, and GCS were taken from the $\mathrm{KCH}$ trauma database. Although outcome at time of discharge was captured (discharged/died/transferred/absconded), functional outcomes were not available for this population.

We performed bivariate analysis on the basis of mortality and adjusted logistic regression to identify predictors of mortality in the total population of TBI patients, as well as descriptive statistics of the population who underwent the exploratory burr hole procedure. All analyses were performed using Stata/IC I4.I (StataCorp, College Station, Texas, USA).

To be considered a candidate for exploratory burr holes, patients were required to have a deteriorating level of consciousness and lateralizing sign on neurological examination and age between 2 and 80 years old. Patients younger than 2 years of age still have open fontanels and would therefore undergo ultrasound to rule out intracranial hematomas. Patients older than 80 years of age were generally not considered operative candidates, given the limitations of resources in our setting, and were managed by the palliative care team. Patients undergoing exploratory burr holes did not receive preoperative CT scans. Before 2013, a CT scanner was not available at $\mathrm{KCH}$. After the arrival of the CT scanner, availability was still unreliable due to personnel and power issues.

\section{Setting}

$\mathrm{KCH}$ is a rooo-bed tertiary care center serving a catchment of 6 million people in Lilongwe, Malawi. One consultant neurosurgeon is on staff, as well as a general surgery residency. A highdependency unit (HDU), with electronic monitoring and a higher nurse-to-patient ratio, is available. There is also a 5-bed intensive care unit (ICU) with mechanical ventilation. Before 2013, the only available imaging modalities were radiographs and ultrasonography. A CT scanner became available in 2013. Basic laboratory investigations are also available. The availability of both radiology and laboratory studies was not constant due to resource limitations and staffing issues.

\section{Exploratory Burr Hole Technique}

The consultant neurosurgeon at $\mathrm{KCH}$ either performed the procedure or supervised general surgery residents performing the procedure. Procedures were most often done in the operating room under general anesthesia. If operating room time or an anesthesia provider was unavailable and the patient's condition was critical, the procedure was done under local anesthesia at the bedside in the ICU. The patient's hair was shaved, and the scalp was washed with alcohol and iodine. A sterile field was prepared. An incision of $\approx \mathrm{I} \mathrm{cm}$ was made down to the bone. A selfretaining retractor was placed, and the periosteum was removed. A Hudson-Brace hand drill with a perforator bit was used to drill the hole as an assistant held the head firmly in place. After reaching the inner table of the skull, the drill was removed from the wound and a hemostat was used to remove the bone chip. If a hematoma was visualized, it was evacuated and the wound was washed out with normal saline and suctioning. If the dura was torn or appeared discolored, suggestive of subdural hematoma, a small cruciate incision was made in the dura and the hematoma was evacuated. Intravenous tubing was sometimes inserted into the opening in order to reach all aspects of the hematoma with a normal saline wash. When a hematoma was identified, the burr hole was sometimes enlarged up to $2 \mathrm{~cm}$, using a round burr drill bit or a bone rongeur, in order to a facilitate a thorough evacuation.

A temporal burr hole was done first, ipsilateral to the fixed and dilated pupil, if unilateral (see Figure 1). If pupils were bilaterally affected, the burr hole was placed on the side of the first pupil to 


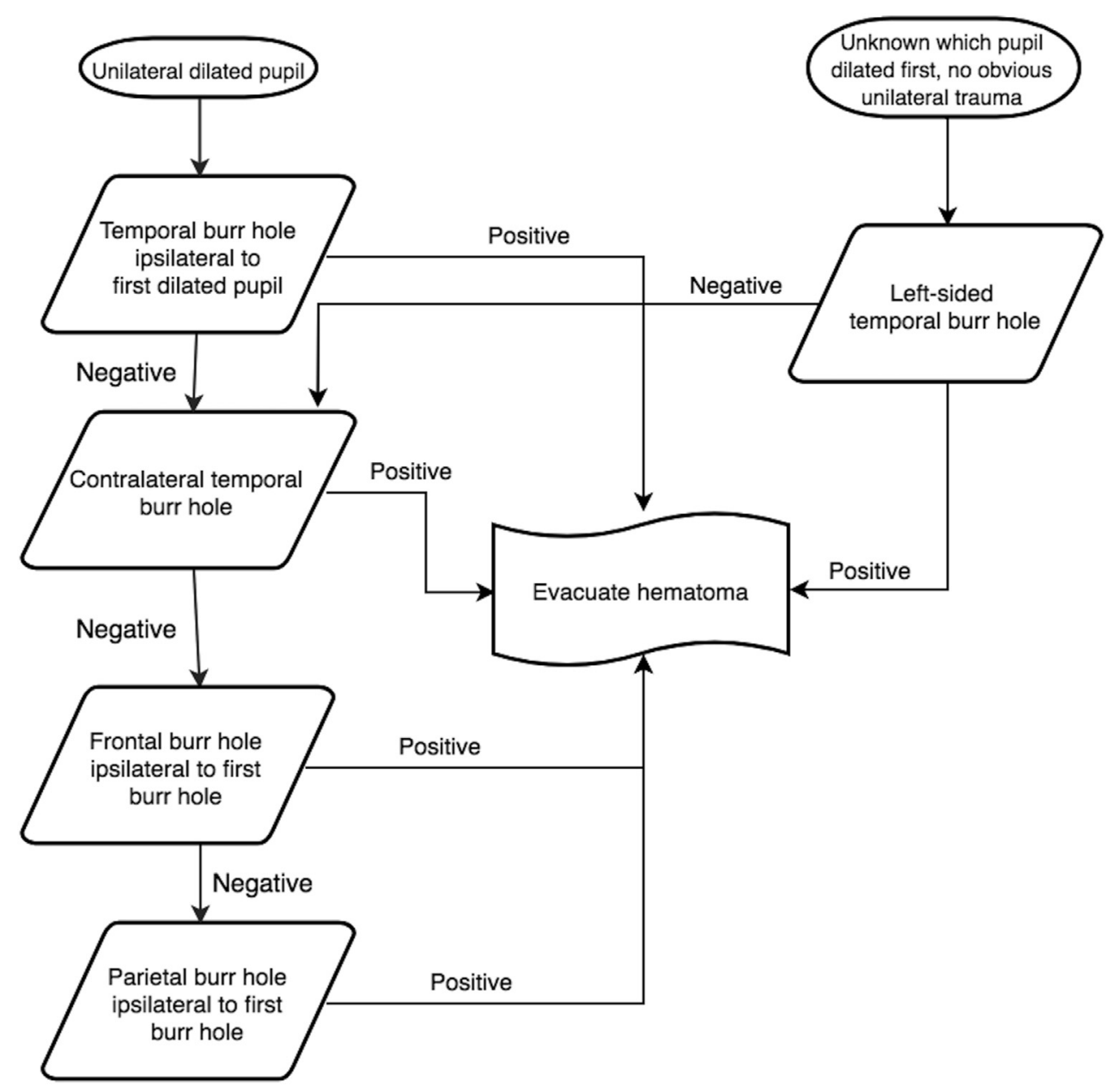

Figure 1. Algorithm for placement of exploratory burr holes.

dilate, if known, or on the side of obvious trauma. If none of these were known, a left-sided burr hole was done first to more quickly reach the likely dominant hemisphere, since $90 \%$ of the population is right-handed, and approximately $95 \%$ of right-handed patients have a dominant left hemisphere. ${ }^{I 7}$ The temporal burr hole was done over the middle cranial fossa, just superior to the zygomatic arch, the most common site of epidural hematomas, which also allows access to most subdural hematomas. If negative, a temporal burr hole was performed on the contralateral side. If the contralateral burr hole was also negative, a frontal burr hole ipsilateral to the initial temporal burr hole was performed. The frontal burr hole was placed 2-3 $\mathrm{cm}$ lateral to the midline at the midpupillary line, $\mathrm{I} \mathrm{cm}$ anterior to the coronal suture. If the frontal burr hole was negative, a subgaleal drain was left in place and the wounds were sutured and dressed. Postoperatively, the patients received frequent neurologic checks, mechanical ventilation or oxygen therapy as indicated, as well as placement of a nasogastric tube, elevation of the head of the bed, seizure prophylaxis as indicated, and pain management.

\section{RESULTS}

A total of 24I patients presented to $\mathrm{KCH}$ with $\mathrm{TBI}$ requiring higher-level care (Table 1). The population was $83.5 \%$ male, and the most common mechanism of injury was road traffic crash (55.2\%). The mean GCS of all TBI patients was $8.7 \pm 3.1$, and total mortality was $\mathrm{I} 6.4 \%$.

From January I through December 3I, 20II, a total of 886 patients were admitted to $\mathrm{KCH}$ with a primary diagnosis of head injury following trauma. Of these, 78 of them $(8.8 \%)$ required higher-level care in either the HDU or ICU. The mean GCS of these patients was I0.2 \pm 4.4 . Mortality of these patients, who did not undergo exploratory burr hole, was $43.9 \%$. In contrast, patients who underwent exploratory burr holes $\left(n=16_{3}\right)$ had a mean GCS of $8.2 \pm 2.4$ and a mortality of $6.8 \%$. Both populations were 


\begin{tabular}{|c|c|c|c|c|}
\hline Patient Characteristics & $\begin{array}{l}\text { All TBI Patients Requiring } \\
\text { HDU/ICU Admission }(n=241)\end{array}$ & $\begin{array}{l}\text { Patients Who Underwent } \\
\text { Exploratory Burr Hole }(n=163)\end{array}$ & $\begin{array}{l}\text { Patients Who Did Not Undergo } \\
\text { Exploratory Burr Hole }(n=78)\end{array}$ & $P$ Value \\
\hline Age (years) & $27.5 \pm 15.1$ & $26.4 \pm 14.4$ & $29.9 \pm 16.9$ & 0.099 \\
\hline Sex & & & & 0.068 \\
\hline Male & $197(83.5 \%)$ & $125(80.1 \%)$ & $70(89.7 \%)$ & \\
\hline Female & $39(16.5 \%)$ & $31(19.9 \%)$ & $8(10.3 \%)$ & \\
\hline Mechanism of injury & & & & 0.000 \\
\hline Assault & $47(19.7 \%)$ & $37(22.7 \%)$ & $10(13.2 \%)$ & \\
\hline Fall & $35(14.5 \%)$ & $26(16.0 \%)$ & $9(11.8 \%)$ & \\
\hline RTI & $132(55.2 \%)$ & $81(49.7 \%)$ & $51(67.1)$ & \\
\hline Unknown/Other & $25(10.5 \%)$ & $19(11.7 \%)$ & $6(7.9 \%)$ & \\
\hline Glasgow Coma Score at admission & $8.7 \pm 3.1$ & $8.2 \pm 0.2$ & $10.1 \pm 0.58$ & 0.000 \\
\hline Overall mortality & $36(16.4 \%)$ & $11(6.8 \%)$ & $25(43.9 \%)$ & 0.000 \\
\hline
\end{tabular}

predominantly young men, and the most common mechanism of injury in both groups was road traffic crash. Other common mechanisms of injury were falls and assaults.

Signs prompting the operation, intraoperative findings, and functional outcomes were recorded for patients who underwent exploratory burr holes (Table 2). At presentation, $40 \%$ of patients had a dilated pupil with contralateral hemiparesis, $27 \%$ had a single dilated pupil with ipsilateral hemiparesis, $23.9 \%$ had only a unilateral dilated pupil, and $8.6 \%$ of patients had bilateral dilated pupils. During the procedure, $5 \mathrm{I} .2 \%$ of patients were found to have subdural hematomas, $13 \%$ had both an epidural and a subdural hematoma, $12.4 \%$ had contusions of the brain, $7.4 \%$ had epidural hematomas, and $3.7 \%$ had subdural hygromas. No operative findings existed in $12.4 \%$ of the patients. Some patients were able to undergo postoperative CT scanning. These findings are listed in Table 2.

For patients who received exploratory burr holes and survived, functional outcomes were assessed at time of discharge as defined by the Glasgow Outcome Scale. ${ }^{16}$ Of the $93.2 \%$ of patients who survived, $5 \mathrm{I} .4 \%$ had a good recovery, with minimal deficits. A small number (10.3\%) of surviving patients had moderate disabilities, which allowed them to live independently. Of the surviving patients, $9.7 \%$ had severe disabilities and would require assistance with activities of daily life, and $15.5 \%$ of the survivors were in a vegetative state at the time of discharge.

We performed bivariate analysis based on mortality on the total population (Table 3). Statistically significant differences were seen in age, GCS, and placement of burr holes between the survived and deceased populations, with patients who died tending to be older and presenting with a lower GCS. Exploratory burr holes were performed on $82.6 \%$ of patients who survived versus $30.6 \%$ of patients who died.

Upon unadjusted logistic regression, decreased age (odds ratio $[\mathrm{OR}]=\mathrm{I} .04,95 \%$ confidence interval $[\mathrm{CI}]=\mathrm{I} .02-\mathrm{I} .07)$, increased GCS $(\mathrm{OR}=0.55,95 \% \mathrm{CI}=0.18-\mathrm{I} .67)$ and placement of exploratory burr holes $(\mathrm{OR}=0.09,95 \% \mathrm{CI}=0.04-0.2 \mathrm{I})$ were associated with a statistically significant decrease in the odds of mortality. Not having undergone exploratory burr holes was associated with significantly increased odds of mortality $(\mathrm{OR}=10.8[95 \% \mathrm{CI} 4.82-24 . \mathrm{I} 5])$. We then constructed a fully adjusted logistic regression, adjusting for age, sex, GCS, and placement of exploratory burr holes. In the adjusted model, decreased GCS (OR $=\mathrm{I} .2 \mathrm{I}, 95 \% \mathrm{CI}=\mathrm{I} .05-\mathrm{I} .39)$ and not undergoing exploratory burr holes $(\mathrm{OR}=\mathrm{I} 2.0,95 \% \mathrm{CI}=4.5-3 \mathrm{I} .8)$ were the only variables associated with a statistically significant increase in the odds of mortality (Table 4).

\section{DISCUSSION}

This study describes our experience with diagnostic and therapeutic exploratory burr holes in moderate to severe TBI in a subSaharan African tertiary care center. While this procedure is generally viewed as archaic, ${ }^{9}$ we have shown its utility and benefit in our resource-poor setting, where adjunctive diagnostic imaging modalities, invasive intracranial monitoring, and targeted therapeutic neurosurgical options are limited.

Optimal management of TBI begins at the first point of contact with the health care system and entails prevention of secondary brain injury. Evidence-based guidelines for best practices in managing these patients are widely accepted ${ }^{\mathrm{I} 8}$ and are mainly aimed at preventing secondary brain injury due to hypoxemia, hypotension, hyperthermia, hypoglycemia, and infection. ${ }^{19}$ The utility of the burr hole is in the prevention and treatment of increased intracranial pressure by evacuating an extra-axial hematoma, which is a significant cause of secondary brain injury. When the ICP increase caused by an expanding mass surpasses the brain's ability to autoregulate by forcing blood and cerebrospinal fluid out of the skull, the intracranial pressure will rise quickly, further damaging the tissue and worsening edema, causing even higher levels of ICP, until the brain begins to 
Table 2. Presentation and Findings in Exploratory Burr Hole

Patients

$\begin{array}{cc} & \text { Patients Who } \\ \text { Characteristics } & \text { Underwent Exploratory } \\ \text { Burr Hole }(n=163)\end{array}$

\begin{tabular}{|lc|}
\hline Signs & $14(8.6 \%)$ \\
\hline Bilateral dilated pupils & $44(27.0 \%)$ \\
\hline Dilated pupil with ipsilateral hemiparesis & $65(39.9 \%)$ \\
\hline Dilated pupil with contralateral hemiparesis & $39(23.9 \%)$ \\
\hline Unilateral dilated pupil & \\
\hline Perioperative Findings & $20(12.4 \%)$ \\
\hline Contusions & $12(7.4 \%)$ \\
\hline Epidural hematoma & $21(13.0 \%)$ \\
\hline Epidural and subdural hematoma & $83(51.2 \%)$ \\
\hline Subdural hematoma & $6(3.7 \%)$ \\
\hline Subdural hygroma & $20(12.4 \%)$ \\
\hline No intraoperative findings & \\
\hline CT scan findings (n $=20)$ & $3(15 \%)$ \\
\hline Diffuse axonal injury & $4(20 \%)$ \\
\hline Subarachnoid hemorrhage & $7(35 \%)$ \\
\hline Skull fracture & $5(25 \%)$ \\
\hline Brain contusions & $1(5 \%)$ \\
\hline Diastasis of cranial sutures & $18(11.0 \%)$ \\
\hline Glasgow Outcome Score at discharge/death & $17(10.4 \%)$ \\
\hline Good recovery & $11(6.8 \%)$ \\
\hline Moderately disabled & \\
\hline Severely disabled & \\
\hline Vegetative state & \\
\hline Death & \\
\hline CT, computed tomography. & \\
\hline
\end{tabular}

herniate down through the tentorium cerebelli, compressing the brainstem and leading to brain death.

In order to prevent the devastating consequences of increased ICP, the most critical element of TBI management is the thorough and frequent neurologic examination. If performed accurately, a precipitous rise in ICP can be detected. Following a TBI, a sudden change in the patient's examination, in the form of a decreased level of consciousness or development of lateralizing signs, is an indication to investigate the possibility of an expanding intracranial hematoma. ${ }^{9}$ In patients who were verbally communicative on admission to the hospital, a rapid deterioration in mental status is due to an intracranial hematoma in approximately $75 \%$ of patients. ${ }^{20}$

Mortality is markedly affected by time to operative intervention, with hematomas needing to be evacuated within 4 hours of injury to prevent poor neurologic outcome. ${ }^{8}$ Before the invention of the CT scanner in 1972, neurosurgeons relied on clinical signs of intracranial pressure to prompt exploration and decompression of the brain following trauma. When herniation seemed imminent, Burton and Blacker advocated for bedside trephination using a hand twist drill in order to save the lives of patients whose "survival could be measured in minutes." ${ }^{21}$ By the I980s, CT scans were routinely performed on patients presenting to major medical centers in high-income countries with severe head injuries. However, some physicians found that the delay caused by obtaining a scan was unacceptable for some clinical scenarios. Therefore I center performed exploratory burr holes without waiting for a CT scan in roo patients with severe TBI and evidence of upper brainstem dysfunction, finding an extraaxial hematoma in $56 \%$ of patients. ${ }^{22}$

Critics of methods of decompression that are performed without preoperative head CT scans argue that clinical signs of extra-axial hematomas are not reliable enough to be used as the sole means of locating a lesion with necessary precision, ${ }^{23,24}$ and while emergency decompression may be justified, a CT scan is required for planning the procedure. However, in LMICs, where CT scanners remain largely unavailable, exploratory burr holes continue to play a significant role in both diagnosis and therapy. ${ }^{\mathrm{I}, \mathrm{I}, \mathrm{I}}$

Reports from settings similar to ours, in which diagnostic adjuncts are either transiently or permanently unavailable, have come from American Samoa ${ }^{\mathrm{I} 3}$ and India ${ }^{\mathrm{I2}}$ in the late 1980 and from $B^{2} n^{14}$ in 2013. In each study, surgeons performed exploratory burr holes, sometimes expanding to emergency craniotomies, based on clinical evidence of early transtentorial herniation. Of note, general surgeons performed all procedures described in the study from American Samoa, as no neurosurgeon lives on the island. These centers reported extraaxial hematomas amenable to decompression in $50.9 \%,{ }^{\mathrm{I}}$ $55.6 \%$, ${ }^{\mathrm{II}}$ and $65.2 \%{ }^{\mathrm{I} 4}$ of severe TBI patients, respectively. Associated mortality was $18.0 \%$ in American $\mathrm{Samoa}^{\mathrm{I} 3}$ and $39.1 \%$ in Benin. ${ }^{\text {I4 }}$

We found extra-axial hematomas amenable to evacuation in $75.2 \%$ of our patients. Negative explorations, in which no significant pathology was seen after placing all 4 burr holes, was $12.4 \%$. These patients' clinical picture was likely cerebral edema as a result of diffuse axonal injury, which carries a poor prognosis regardless of intervention. ${ }^{6}$ A small group of our patients had intraoperative findings but did not have extra-axial hematomas and unfortunately were not helped by surgical intervention, aside from the benefit provided by the release of pressure facilitated by the burr holes. The same effect caused by extra-axial intracranial hematomas can be caused by brain contusions or localized edema, which are not amenable to burr hole evacuation. Additionally, there is the possibility of "false" localizing signs, such as hemiparesis ipsilateral to a dilated pupil, caused by the shift of the brainstem and compression of the contralateral cerebral peduncle against the tentorium. ${ }^{6}$

In our resource-poor setting, because of limitations of operating room access and limited anesthesia and surgical providers, a formal craniotomy or other definitive procedure is most often not possible. With $66.2 \%$ of our patients having favorable outcomes with exploratory burr hole alone (either good recovery or mild disability), our intervention provides acceptable results, given our limited resources. 
Table 3. Bivariate Analysis of Total Population by Mortality

\begin{tabular}{|c|c|c|c|}
\hline Variable & $\begin{array}{c}\text { Survived ( } \mathrm{n}=184 \text { ) } \\
\text { (mean or median [SD, IQR]) }\end{array}$ & Died $(n=36)$ & $P$ Value \\
\hline Age & $26.1 \pm 13.8$ & $36.1 \pm 18.7$ & 0.000 \\
\hline Male sex & $144(81.4 \%)$ & $32(88.9 \%)$ & 0.277 \\
\hline \multicolumn{4}{|l|}{ GCS } \\
\hline Mild-moderate TBI (GCS 9-13) & $90(51.7 \%)$ & $9(31.0 \%)$ & 0.039 \\
\hline Severe TBI $(\mathrm{GCS} \leq 8)$ & $84(48.3 \%)$ & $20(69.0 \%)$ & 0.039 \\
\hline Mechanism of injury & & & 0.343 \\
\hline Fall & $32(17.6 \%)$ & $2(5.6 \%)$ & \\
\hline Road traffic crash & $95(52.5 \%)$ & $21(58.3 \%)$ & \\
\hline Assault & $38(20.9 \%)$ & $9(25.0 \%)$ & \\
\hline Other/Unknown & $17(9.3 \%)$ & $4(11.1 \%)$ & \\
\hline Exploratory burr holes placed & $152(82.6 \%)$ & $11(30.6 \%)$ & 0.000 \\
\hline
\end{tabular}

Another obstacle to optimal management of TBI patients is created by the inadequate size of the neurosurgical workforce in LMICs. Africa has only I neurosurgeon per 10,000,000 people, compared with 102 in Europe and 56 globally. ${ }^{25}$ In response, initiatives such as training general surgeons to complete basic neurosurgical procedures are being explored. In Tanzania, general surgeons have been trained in procedures to treat hydrocephalus, TBI, and mass lesions of the brain and spinal cord with good results. ${ }^{26}$ Critics of these programs argue that general surgeons will not be appropriately prepared to handle complications of neurosurgery and that nonemergent patients can and should be referred to neurosurgical centers. ${ }^{27}$ It is therefore important to note that the patients reported here represent true surgical emergencies and, without intervention, they would die. Further, we have demonstrated that simple burr holes provide good results, even without a subsequent craniotomy. This is a straightforward procedure that general surgeons can easily be trained to perform safely and effectively.

\begin{tabular}{|c|c|c|c|}
\hline Variable & Odds Ratio & $P$ Value & $\begin{array}{l}\text { 95\% Confidence } \\
\text { Interval }\end{array}$ \\
\hline Age & 1.03 & 0.09 & $0.99-1.06$ \\
\hline Female sex & 0.57 & 0.44 & $0.14-2.35$ \\
\hline Presence of severe TBI (GCS $\leq 8)$ & 3.21 & 0.02 & $1.20-8.64$ \\
\hline Exploratory burr holes placed & 0.10 & 0.00 & $0.04-0.25$ \\
\hline Exploratory burr holes not placed & 10.3 & 0.00 & $3.95-26.76$ \\
\hline
\end{tabular}

The limitations of our study are those inherent to any study with a retrospective methodology. Additionally, in choosing the population of patients who did not undergo the procedure, we were limited to identifying TBI patients based only on the fact that the patient's most severe injury was to the head or face. Without radiographic or more specific clinical data, we were unable to identify TBI patients more specifically. We also cannot be sure that all patients who received care in the HDU or ICU would have been candidates for exploratory burr holes. Lastly, we were unable to do a complete comparison, as the $\mathrm{KCH}$ trauma database did not provide all of the same variables as the data collected on the exploratory burr hole patients.

The placement of exploratory burr holes may be a life-saving technique in a resource-poor or austere environment. They may also provide an important intervention in high-income centers, when the condition of the patient does not allow time for diagnostic scanning or transport for a more definitive treatment. This is a technique that is accessible to general surgeons and should be incorporated within general surgical training.

\section{CONCLUSION}

In our resource-poor setting, clinical and functional outcomes following exploratory burr holes in patients with TBI is favorable, and it justifiably remains a mainstay of treating TBI in LMICs. In settings where access to CT scanners and neurosurgical expertise is limited, training general surgeons in exploratory burr hole technique is imperative in order to decrease TBI-related mortality.

\section{ACKNOWLEDGMENTS}

We are grateful to the Department of Surgery and the Trauma Registry staff at $\mathrm{KCH}$ for their hard work and support of this research. We are particularly grateful to Drs. Enock Ludzu and Judith Mkwaila for their dedication to the care of the patients reported here. 


\section{REFERENCES}

I. Global, regional, and national life expectancy, allcause mortality, and cause-specific mortality for 249 causes of death, 1980-2015: a systematic analysis for the Global Burden of Disease Study 20I5. Lancet. 20I6;388:I459-I544.

2. Injury: a leading cause of the global burden of disease. Injury. 2000;2000:I-5I. Available at: http://www.who. int/violence_injury_prevention/publications/other_ injury/injury/en/. Accessed June I7, 2017.

3. de Ramirez SS, Hyder AA, Herbert HK, Stevens K. Unintentional injuries: magnitude, prevention, and control. Annu Rev Public Health. 2012;33: I75-I9I.

4. Capone-Neto A, Rizoli SB. Linking the chain of survival: trauma as a traditional role model for multisystem trauma and brain injury. Curr Opin Crit Care. 2009;15:290-294.

5. Gunnarsson T, Fehlings MG. Acute neurosurgical management of traumatic brain injury and spinal cord injury. Curr Opin Neurol. 2003;16:717-723.

6. Houseman CM, Belverud AS, Narayan RK. Closed head injury. In: Ellenbogen RG, Abdulrauf SI, Sekhar LN, eds. Principles of Neurosurgery. 3rd ed. Philadelphia, PA: WB Saunders; 2012:325-348.

7. Stone JL, Jonasson O, Baker RJ, Barrett J, Oldershaw JB. Acute subdural hemtoma: direct admission to a trauma center yields improved results. J Trauma. I986;26:445-450.

8. Seelig JM, Becker DP, Miller D, Greenberg RP, Ward JD, Choi SC. Traumatic acute subdural hematoma: major mortality reduction in comatose patients treated with four hours. N Engl J Med. I98I;304:I5II-I5I8.

9. Greenberg MS. Head trauma. In: Greenberg MS, ed. Handbook of Neurosurgery. New York, NY: Thieme; 2010:850-929.

Io. WHO. Global forum to improve developing country access to medical devices in World Health Organization Media Centre. Geneva, Switzerland: WHO; 2010.

II. Natarajan M, Asok Kumar N, Jawahar G. Usefulness of exploratory burr holes in the management of severe head injury. J Indian Medl Assoc. I989;87: 256-258.

I2. Nagabhan A, Sangcham K. The study of traumatic intracerebral hematoma at Buri Ram Hospital. J Med Assoc Thailand. 1993;76:399-404.

13. Schecter WP, Peper E, Tuatoo V. Can general surgery improve the outcomeof the head injury victim in rural America? A review of the experience in American Samoa. JAMA Surg. I985;I20: II63-II66.

I4. Fatigba HO, Allode AS, Savi de Tove KM, Mensah ED, Hodonou AM, Padonou J. The exploratory burr hole: indication and results at one departmental hospital of benin. ISRN Surg. 2013;2013:453907.

I5. Samuel JC, Akinkuotu A, Villaveces A, Charles AG, Lee CN, Hoffman IF, et al. Epidemiology of injuries at a tertiary care center in Malawi. World J Surg. 2009;33:I836-I84I.

I6. Jennett B, Bond M. Assessment of outcome after severe brain damage: a practical scale. Lancet. I975;305:480-484.

I7. Knecht S, Deppe M, Drager B, Bobe L, Lohmann H, Ringelstein EB, Henningsen H. Language lateralization in healthy right-handers. Brain. 2000;I23:74-8I.

I8. Brain Trauma Foundation AANS, Congress of Neurological Surgeons, AANS/CNS Joint Section of Neurotrauma and Critical Care. Guidelines for the management of severe traumatic brain injury. J Neurotrauma. 2007;24:I-I06.

I9. Miller JD, Butterworth J, Gudeman SK, Faulkner JE, Choi SC, Selhorst JB, et al. Further experience in the management of severe head injury. J Neurosurg. I98I;54:289-299.

20. Rockswold GL, Pheley PJ. Patients who talk and deteriorate. Ann Emerg Med. I993;22:1004-I007.

2I. Burton C, Blacker H. A compact hand drill for emergency brain decompression. J Trauma. I965;5: $643-646$.

22. Andrews BT, Pitts L, Lovely MP, Bartkowski H. Is computer tomography scanning necessary in patients with tentorial herniation? resulted of immediate surgical exploration without CT in IOO patients. Neurosurgery. I986;I9:408-4I4.

23. Ortler M, Langmayr J, Stockinger A, Golser K, Russegger L, Resch H. Prognosis of epidural hematoma: is emergency burr hole trepanation in craniocerebral trauma still justified today? Unfallchirurg. I993;96:628-63I.

24. Chesnut RM. What is wrong with the tenets un derpinning current management of severe traumatic brain injury? Ann N Y Acad Sci. 2015;1345: $74-82$.

25. Saraceno B, Aarli J, Prilipko L, Saxena S. Atlas: Country Resources for Neurological Disorders. Geneva, Switzerland: WHO; 2004.

26. Coburger J, Leng LZ, Rubin DG, Mayaya G, Medel R, Ngayomela I, et al. Multi-institutional neurosurgical training initiative at a tertiary referral center in Mwanza, Tanzania: where we are after 2 years. World Neurosurg. 20I4;82:eI-e8.

27. El-Fiki M. Local African concerns on multiinstitutional neurosurgical training initiative at a tertiary referral center in Mwanza, Tanzania. World Neurosurg. 2014;82:eI55-I56.

Conflict of interest statement: This work was supported by the Fulbright Program and the National Institutes of Health (NIH) Office of the Director; Fogarty International Center; Office of AIDS Research; National Cancer Center; National Heart, Blood, and Lung Institute; and the NIH Office of Research for Women's Health through the Fogarty Global Health Fellows Program Consortium composed of the University of North Carolina, John Hopkins, Morehouse and Tulane (R25TW009340). The authors report no conflicts of interest concerning the materials or methods used in this study or the findings specified in this paper.

Received 21 March 2017; accepted 24 May 2017

Citation: World Neurosurg. (2017) 105:257-264. http://dx.doi.org/10.1016/j.wneu.2017.05.153

Journal homepage: www.WORLDNEUROSURGERY.org 


\section{APPENDIX: CASE STUDY}

Case 1

LK was a 3I-year-old female patient who presented to our center $>_{\mathrm{I}}$ hour after being involved in a motor vehicle crash. She was a passenger in an open-bed truck. After securing her airway and ensuring hemodynamic stability in the casualty department, she was found to have an initial Glasgow Coma Scale score of 7 , a dilated and sluggishly reactive pupil on the right, and hemiparesis on the left. The patient was noted to have an obvious linear right temporoparietal fracture on plain skull radiography. She was assessed by the neurosurgeon and taken to the operating room within 4 hours of presentation. A right-sided temporal burr hole was placed, and the patient was found to have an extradural hematoma. Approximately $20 \mathrm{~mL}$ of hematoma were evacuated. When the dura was visualized, no pulsation was seen; the dura was therefore carefully opened, and approximately $150 \mathrm{~mL}$ of subdural hematoma were evacuated. Postoperatively, the patient was admitted to the ICU, where she recovered on mechanical ventilation. She was extubated on postoperative day 2 and moved to the step-down unit. She spent an additional 12 days in the hospital undergoing physical therapy before being discharged from the hospital with no neurologic deficits on postoperative day I4.

Case 2

$\mathrm{MN}$ was a 40-year-old male who was transferred to our center from a local clinic 4 hours after being struck by a car while walking in the road. His vitals were stable, and he had no other injuries; however, at the time of the neurosurgeon's assessment he had a GCS of 12 and a nonreactive and dilated right pupil with ipsilateral hemiparesis. He was rushed to the operating room, and a rightsided temporal burr hole was placed. The patient was found to have a large subdural hematoma. The burr hole was enlarged to a diameter of $2 \mathrm{~cm}$, and approximately $200 \mathrm{~mL}$ of hematoma were evacuated. Postoperatively, the patient was stable and recovered in the general ward for 3 weeks before discharge with no neurologic deficits. 